\title{
Incidence of Agrobacterium tumefaciens Biovar 1 in and on 'Paradox' (Juglans hindsii $\times$ Juglans regia) Walnut Seed Collected from Commercial Nurseries
}

\author{
L. E. Yakabe, S. R. Parker, and D. A. Kluepfel, United States Department of Agriculture-Agricultural Research Service Crops Pathol-
} ogy and Genetics Research Unit, Department of Plant Pathology, University of California-Davis 95616

\begin{abstract}
Yakabe, L. E., Parker, S. R., and Kluepfel, D. A. 2014. Incidence of Agrobacterium tumefaciens biovar 1 in and on 'Paradox' (Juglans hindsii × Juglans regia) walnut seed collected from commercial nurseries. Plant Dis. 98:766-770.

The walnut rootstock 'Paradox' (Juglans hindsii $\times$ J. regia) is susceptible to Agrobacterium tumefaciens, which often results in a high incidence of crown gall in nursery or walnut production orchards. Though A. tumefaciens is susceptible to the commonly used preplant soil fumigants, crown gall incidence can rise above acceptable levels. We examined the ability of Paradox seed to acquire A. tumefaciens as a function of harvest method used prior to planting. Over a 2-year period at two participating commercial nurseries, Paradox seed were collected directly from the mother tree without contacting the soil or gathered after

sitting on the orchard floor for up to 28 days. A. tumefaciens was never detected in or on the 2,650 seeds collected directly from the mother tree. Both virulent and avirulent A. tumefaciens strains were detected in and on the husk of nuts incubated on the orchard floor at a frequency directly proportional to the time spent on the orchard floor. Regardless of A. tumefaciens contamination in or on the husk, A. tumefaciens was never detected in the seed interior. Avoiding soilborne populations of A. tumefaciens at the time of seed collection will play an important role in managing crown gall.
\end{abstract}

California nurseries produce over 800,000 English walnut ( $\mathrm{Ju}$ glans regia L.) trees for commercial planting every year (D. A. Kluepfel, unpublished data). Approximately $75 \%$ of these trees are grafted onto Juglans hindsii (Jeps) Rehder $\times$ J. regia 'Paradox' rootstock. Paradox is vigorous, precocious, adaptable to marginal walnut-producing soils, and resistant to multiple species of Phytophthora and tolerant of Pratylenchus vulnus $(4,6,20)$. Paradox, however, is highly susceptible to Agrobacterium tumefaciens (7), the causal agent of crown gall (26). Infected tissues develop extensive tumors which girdle the tree, resulting in disrupted tree vasculature, diverted plant nutrients, and increased susceptibility to secondary diseases (25). The ultimate consequences of this disease are reduced orchard yield and tree longevity (13). Because A. tumefaciens infection may not manifest (i.e., gall formation) for several years, nursery operators take costly measures to prevent introduction of A. tumefaciens into any aspect of walnut tree production $(14,16,17,31)$.

Crown gall incidence in walnut nurseries and production fields has been attributed to soilborne populations of $A$. tumefaciens $(1,3,13,14,20)$. Despite widespread use of methyl bromide as a preplant fumigant, crown gall still occurs. Several studies concluded that methyl bromide is not effective at reducing virulent $A$. tumefaciens populations in soil; however, these studies measured populations of virulent $A$. tumefaciens indirectly by either observing disease development or using media limited in its ability to selectively cultivate $A$. tumefaciens $(9,10,12)$. Using an antibioticresistant marked strain of $A$. tumefaciens, along with a polymerase chain reaction (PCR)-based test to verify virulence, a recent study directly measured populations of $A$. tumefaciens before and after methyl bromide fumigation (30). This study concluded that many preplant fumigants are effective at reducing soilborne populations of $A$. tumefaciens and suggested that A.tumefaciens is reintroduced

Corresponding author: D. A. Kluepfel, E-mail: dakluepfel@ucdavis.edu Accepted for publication 2 December 2013.

http://dx.doi.org/10.1094/PDIS-07-13-0742-RE

This article is in the public domain and not copyrightable. It may be freely reprinted with customary crediting of the source. The American Phytopathological Society, 2014. into the soil through contaminated planting material such as seedlings or seed (31).

Hybrid Paradox rootstock is typically grown from open-pollinated seed which are harvested from black walnut trees (J. hindsii) pollinated by English (J. regia) walnut in a nursery called the "mother block". Nurseries also occasionally purchase Paradox seed from individual collectors who harvest seed from unmanaged black walnut stands. Seed are either hand gathered from the orchard floor of the mother block or collected with a harvester after shaking the canopies of the mother-block trees. The seed are then dried on a pole-barn floor and stored until planting or planted directly into the field and stratified under natural conditions. Paradox seed are not typically treated for pathogen control before planting in a commercial nursery.

Many seedborne pathogens are transferred to the seed from endophytic populations contained in the parent plant or from close proximity of infested plant material. For example, Clavibacter michiganensis subsp. michiganense can establish endophytic populations within tomato plants. Seed produced by these diseased plants are often contaminated with the bacterium on the seed coat and inside the embryo (11). Another example can be found in seed of cruciferous vegetables which can be infested with Xanthomonas campestris pv. campestris $(22,23)$. This bacterium is not present endophytically in the host plant but flowers can become infested with this pathogen, which is readily transferred to the seed (27).

A. tumefaciens is known to be a good soil inhabitant, where it can bind to soil particles and survive for years in the absence of a susceptible host $(1,3,5,15,20)$. Once dried, these A. tumefacienscolonized soil particles, in the form of windborne dust, could potentially transport the bacterium long distances. The ability of $A$. tumefaciens to hitch such a ride commonly occurs with cotton and cotton dust, where A. tumefaciens has been characterized as a "typical cotton fiber-borne bacterium" (24).

Because seed come in contact with the orchard floor during traditional Paradox seed collection, the probability of being infested by soilborne populations of A. tumefaciens is elevated. Additionally, crown gall on trees in the mother block serves as a reservoir of A. tumefaciens inoculum. This enhances the likelihood of infection of walnut seed dropped to the orchard floor at harvest. Finally, during seed handling, it has been hypothesized that A. tumefacienscontaminated soil may come in contact with the seed through dust in bins, buckets, and drying room floors. In addition, it is not 
known whether this bacterium, which we and others have shown can exist endophytically in walnut trees, can be transferred through the vascular system of infected mother trees into the seed $(8,33)$.

To date, the occurrence and importance of A.tumefaciens-contaminated Paradox seed have not been evaluated in the walnut industry. To address this concern, we designed this study to investigate the incidence and source of A. tumefaciens infection of Paradox seed and its impact on crown gall formation on young seedlings. Understanding the ecology and epidemiology of $A$. tumefaciens on walnut seed will greatly improve existing crown gall management strategies.

\section{Materials and Methods}

Mother block surveys. The incidence of A. tumefaciens in or on walnut seed was assessed by surveying a mother block of Paradox trees (J. hindsii; northern California black walnut) in each of two commercial nurseries. Mother blocks were located in Stanislaus and Colusa Counties, CA. Surveys were initiated when walnut seed were determined to be ripe and in the "brown tissue" stage (21). Sampling started on 8 September 2009 and 29 September 2009 in the Stanislaus and Colusa County mother blocks, respectively. The following year, sampling started on 21 September 2010 and 14 October 2010 in the Stanislaus and Colusa County mother blocks, respectively.

In all, 40 walnut seeds were collected from the boughs of 16 black walnut trees using a cherry picker, reaching the upper levels of the canopy. The seed were shaken directly into virgin paper bags and sealed immediately. These seed were handled aseptically through the entire process. Half of the trees were symptomatic, with galls present at the crown in the Stanislaus County mother block. The other half was asymptomatic. None of the trees in the mother block in Colusa County were symptomatic for crown gall.

We defined a nut or seed as consisting of two parts: (i) exterior of the shell (exterior; i.e., from the green seed surface down through the husk to the shell surface) and (ii) the interior of the shell (interior; i.e., everything inside the shell). For each tree, 20 seeds, in sets of 4 , were rubbed onto $1 \mathrm{~A}$, a semiselective medium for Agrobacterium spp., which contained tellurite at $80 \mathrm{ppm}$ and cyclohexamide at $100 \mathrm{ppm}$, to assay the exterior of the seed $(19,31,33)$. Subsequently, the interior of the seed were assayed by removing the husk, surface sterilizing the shell surface in $20 \%$ ( $\mathrm{vol} / \mathrm{vol}$ ) bleach for $10 \mathrm{~min}$, rinsing in deionized water, and then smashing the seed with a hammer in a sealed plastic bag in groups of four. Sterile water $(10 \mathrm{ml})$ was added to the crude extract and $1.5 \mathrm{ml}$ was plated onto $1 \mathrm{~A}$. The second set of 20 seeds was artificially stratified for subsequent grow-out assays examining crown gall development on seedlings.

Artificial stratification consisted of packing seed in 1-gal. (3.8 liter) plastic bags containing moist peat moss (1 part water to 2 parts peat moss [vol/vol]) and storing them in the dark at $6^{\circ} \mathrm{C}$ for 2 to 6 months. The open end of the bag was folded over and secured with a rubber band to allow air exchange.

An additional 1,600 seeds were randomly picked from trees throughout the mother block and placed on the ground under eight trees in groups of 200 seeds. All eight trees in the Stanislaus County nursery had crown gall symptoms and consisted of both English and black walnut trees. In the Colusa County nursery mother block, four trees were symptomatic English walnut and four trees were asymptomatic black walnut trees. Groups of 40 seeds from each tree were collected 1, 3, 7, 14, and 28 days after placing the seed directly on the orchard floor under the selected trees. The seed were partitioned for culturing (20 seeds) or growout tests (20 seeds), as described previously. The seed interiors were assayed only at the first time point (directly picked off the tree) and the last time point (left on the orchard floor).

At the early time points, colonies isolated on 1A agar medium were subcultured onto fresh $1 \mathrm{~A}$ and identified as biovar 1 by Benedict's test (or 3-ketolactose test; 2,18) and tested for tumor-forming ability via PCR using previously described T-DNA-specific Tip6 primers (30). Bacteria were randomly harvested from plates using a $2-\mu l$ loop at later time points. This bacterial mixture was suspended in water and assayed for the presence of virulent A. tumefaciens biovar 1 strains using Benedict's test and Tip6 PCR.

Incidence of virulent and avirulent $A$. tumefaciens was pooled across nursery and sampling year to assess for trends. Data were subjected to a regression analysis using PROC REG in SAS 9.1 (SAS Institute). The incidence of virulent $A$. tumefaciens on seed placed next to symptomatic trees and asymptomatic trees in the Colusa County nursery mother block were subject to an analysis of variance (ANOVA) using PROC GLM in SAS. The year data that were collected did not significantly contribute to the variation; thus, data from both years were pooled in the analysis.

Seed were stratified for 4 to 6 months, as described above, and then planted in 6-in. $(15.24 \mathrm{~cm})$ pots containing steam-pasteurized planting media (equal parts Supersoil/perlite/peat moss) for growout tests. Planted seed were germinated and grown in a greenhouse for approximately 1 year. Germination percentage and crown gall symptom development were recorded. Data was subject to a chisquared analysis with a significance level of $P \leq 0.0056$.

To maintain anonymity, county locations are given but cooperating nurseries are simply labeled nursery A and nursery B.

Inoculum. In greenhouse experiments, the rifampicin-resistant mutant of A. tumefaciens biovar 1, strain 186r was used. The wild type was originally isolated from a surface-sterilized walnut seedling stem section of a Paradox seedling exhibiting crown gall symptoms in Stanislaus County, CA. Except for growth in the presence of rifampicin, 186r was confirmed to be indistinguishable from its wild type, in terms of antibiotic resistance profile and growth rate in minimal media (31).

A. tumefaciens $186 \mathrm{r}$ inocula were prepared by adding a 3-ml loop of a 48-h A. tumefaciens culture grown on trypticase soy broth agar (TSBA; trypticase soy broth at $30 \mathrm{~g} \mathrm{liter}^{-1}$ and bacto agar at $15 \mathrm{~g} \mathrm{liter}^{-1}$; Difco Bacto BBL) amended with rifampicin sulfate at $100 \mathrm{ppm}$ (TSBA+rif) to either a 3- or 200-ml flask of trypticase soy broth $\left(30 \mathrm{~g} \mathrm{liter}^{-1}\right)$, depending on inoculum needs. The liquid cultures were incubated at $28^{\circ} \mathrm{C}$ on a rotary shaker $(200 \mathrm{rpm})$ for $48 \mathrm{~h}$. The bacterial suspension was pelleted at $5,468 \times g$ for 10 $\mathrm{min}$. The resulting pellets were washed twice using sterile distilled water. Final suspensions of washed cells were spectrophotometrically (optical density at $600 \mathrm{~nm}$ ) adjusted to $1 \times 10^{8} \mathrm{CFU} / \mathrm{ml}$ and used as inoculum.

Datura seed. To evaluate A. tumefaciens transfer from mother plant to seed, Datura stramonium was used as a model system. $D$. stramonium is highly susceptible to A. tumefaciens and is used as an indicator plant for crown gall. D. stramonium seedlings were either planted in $186 \mathrm{r}$-infested soil $\left(1 \times 10^{8} \mathrm{CFU} / \mathrm{ml}\right)$ or wounded on the stem with a scalpel blade dipped in $186 \mathrm{r}$ inoculum $\left(1 \times 10^{8}\right.$ $\mathrm{CFU} / \mathrm{ml})$. D. stramonium plants planted in noninoculated soil and not wounded were used as negative controls. Two trials contained 12 plants each.

Six months after inoculation, four plants from each treatment were destructively sampled to determine whether $186 \mathrm{r}$ was detectable in plant stems. Three 5 -cm segments of each plant were plated on TSBA+rif and incubated at $28^{\circ} \mathrm{C}$ for $48 \mathrm{~h}$. The remaining plants were kept until seed were produced. Seed were collected directly from seed pods. Fifteen seeds from each plant were placed in extraction bags (Agdia) and crushed with a hammer. Phosphatebuffered saline $(2 \mathrm{ml} ; 137 \mathrm{mM} \mathrm{NaCl}, 2.7 \mathrm{mM} \mathrm{KCl}, 3.2 \mathrm{mM}$ $\mathrm{Na}_{2} \mathrm{HPO}_{4}, 0.5 \mathrm{mM} \mathrm{KHPO}{ }_{2} ; \mathrm{pH}$ 7.2) plus $20 \mathrm{mM}$ ascorbic acid was added to create a slurry. The slurry $(1.5 \mathrm{ml})$ was plated onto TSBA+rif and incubated at $28^{\circ} \mathrm{C}$ for $48 \mathrm{~h}$ followed by $48 \mathrm{~h}$ at $22^{\circ} \mathrm{C}$. Diagnostic A. tumefaciens colonies were tallied after the 4day incubation. This two-step incubation approach facilitated enhanced $A$. tumefaciens $186 \mathrm{r}$ detection.

Greenhouse simulation of nursery mother block studies. To provide evidence of $A$. tumefaciens transfer from soil to walnut seed and to localize A. tumefaciens inoculum in or on walnut seed tissue, walnut seed were placed on top of 186r-amended soil, where they remained for 110 days. Soil was collected from a walnut production orchard in Yolo County, CA and a nursery mother 
block orchard in Stanislaus County, CA. Each soil type (14 liters) was inoculated separately to a final concentration of A. tumefaciens $186 \mathrm{r}$ at $2 \times 10^{5} \mathrm{CFU} / \mathrm{g}$ of soil, mixed thoroughly using a hand trowel, and placed in a 60-by-45-by-10-cm metal tray with drainage holes. Negative controls consisted of 8 liters of noninoculated soil from both sources similarly mixed and placed in 40-by-30-by$10-\mathrm{cm}$ metal trays with drainage holes. Walnut seed used in this experiment were collected directly from trees in the Stanislaus County nursery mother block of black walnut trees. In all, 20 seeds were assayed as described below while 120 seeds were placed on the surface of each of the inoculated soils and 30 were placed on the surface of the noninoculated soils.

Seed were assayed 1, 4, 7, 14, 21, 28, and 108 days after being placed on the soil surface. Ten seeds were collected from the surface of each inoculated soil tray and destructively sampled. Three seeds were destructively sampled from each noninoculated soil treatment. The exterior surface of the green seed, internal husk material, and interior of the seed (shell and nut meat) were assayed individually for A. tumefaciens. To assay the exterior portion of the green seed, the surface was cleared of large soil clods and then rubbed onto TSBA+rif and 1A agar media. Subsequently, the surface of the green seed was surface sterilized in $20 \%$ bleach (wt/wt) for 5 min on a rotary shaker $(120 \mathrm{rpm})$. After rinsing in three volumes of distilled water, the husk was removed and emulsified in $20 \mathrm{ml}$ of phosphatebuffered saline in an extraction bag (Agdia) using a hammer. The resulting slurry $(1 \mathrm{ml})$ was plated onto TSBA+rif and $1 \mathrm{~A}$.

To assay the interior of the seed, the surface of the shell was scrubbed to remove remaining husk material and surface sterilized in $20 \%$ bleach (wt/wt) for $5 \mathrm{~min}$ on a rotary shaker $(120 \mathrm{rpm})$. The nuts were rinsed with three volumes of distilled water and crushed with a hammer in an extraction bag (BioReba). Buffer $(30 \mathrm{ml})$ was added to create a slurry. Of this slurry, $1 \mathrm{ml}$ was plated onto TBSA+rif and 1A. TSBA+rif was used to detect 186r and 1A to

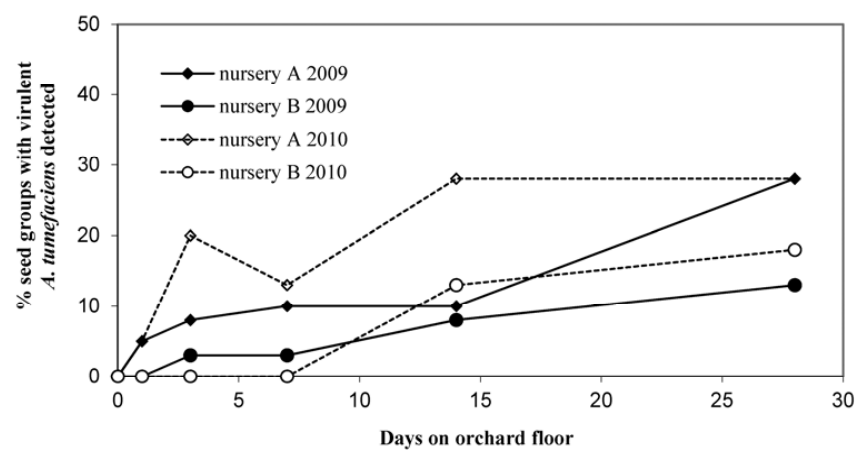

Fig. 1. Proportion of seed groups with viable virulent Agrobacterium tumefaciens strains detected (growth on 1A,3-ketolactose positive and T-DNA positive) after seed were harvested directly from the mother tree (time 0 ) or picked off of the orchard floor (day 1 to 28).

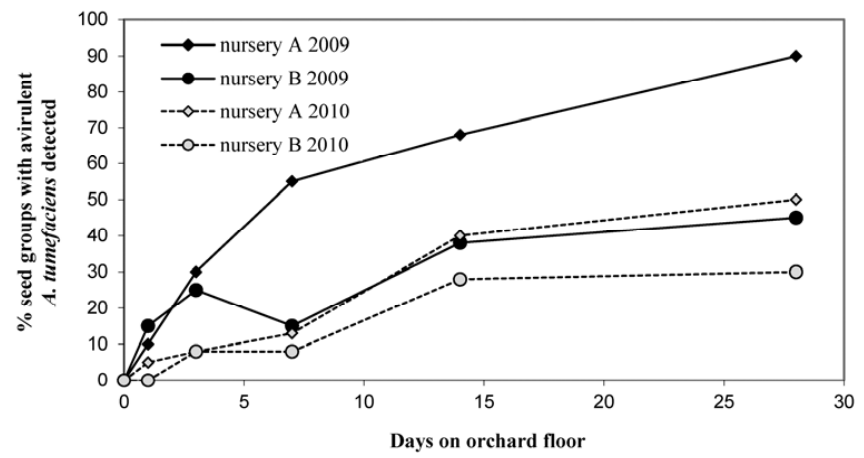

Fig. 2. Proportion of seed groups with viable avirulent Agrobacterium tumefaciens strains detected (growth on 1A, 3-ketolactose positive, and T-DNA negative) after seed were harvested directly from the mother tree (time 0 ) or picked off of the orchard floor (day 1 to 28 ). detect indigenous populations of $A$. tumefaciens. TSBA+ rif plates were incubated at $28^{\circ} \mathrm{C}$ for 2 days and $1 \mathrm{~A}$-containing plates were incubated at $28^{\circ} \mathrm{C}$ for 3 days prior to counting colonies. We confirmed that bleach was not entering the seed using two approaches. First, 10 seeds were soaked in a food color solution for $15 \mathrm{~min}$, followed by cracking and opening to reveal that no dye had penetrated the shell. Second, we frequently isolated a variety of microorganisms from the interior of bleach-treated seed. This would not have occurred if bleach was penetrating the shell.

Colonies on TSBA+rif were verified as 186r by subculturing onto fresh TSBA+rif to ensure rifampicin resistance and by PCR using Tip6 primers to verify virulence (i.e., T-DNA presence; 30). Colonies on $1 \mathrm{~A}$ were identified by subculturing onto $1 \mathrm{~A}$ and verifying as biovar 1 (bv. 1) using the Benedict's test. Bv. 1 isolates determined not to be 186r were screened for virulence using Tip6 primers. Non-A. tumefaciens bv. 1 isolates were identified by $16 \mathrm{~S}$ rDNA sequencing using primers described previously (28).

Seed inoculation studies. To determine whether A. tumefaciens persists in seed husks over the 4- to 5-month stratification period, seed were inoculated with $A$. tumefaciens $186 \mathrm{r}$ and stratified either artificially or naturally. The seed used in these experiments were picked directly from $J$. hindsii trees in a Paradox mother block located in Colusa County. Prior to use, husk material from 10 seeds was plated on TSBA+rif and confirmed to contain no detectable rifampicin-resistant bacteria.

The seed were inoculated by dipping them in a suspension of 186r $\left(6.3 \times 10^{6} \mathrm{CFU} / \mathrm{ml}\right)$ for $10 \mathrm{~min}$ followed by incubation at room temperature for $48 \mathrm{~h}$ before being stratified artificially. Natural stratification methods mimicked procedures used in commercial nurseries, where seed are planted directly in field soil fumigated with 1,3-dichloropropene and chloropicrin (Telone C-35). The field soil used in these trials was collected from the Armstrong experimental fields located at the University of California, Davis and then fumigated with Telone C-35 at the label rate. For these experiments, Paradox seed were planted in 20-cm-diameter pots filled with the fumigated field soil. These pots were then buried approximately $2 \mathrm{~cm}$ deep in a field plot at Armstrong field house, Davis, CA. Both the peat moss and field soil were plated on TSBA+rif and shown to contain no background levels of rifampicin-resistant bacteria.

A. tumefaciens populations residing in the husk material were assayed after $0,2,5,9,17,21$, and 24 weeks of artificial stratification. Husk material $(1 \mathrm{~g})$ was bulked from three random areas of each seed and suspended in $10 \mathrm{ml}$ of sterile, deionized water. The samples were shaken on a rotary shaker $(120 \mathrm{rpm})$ for $10 \mathrm{~min}$. Dilutions were plated on TSBA+rif-containing plates which were incubated at $28^{\circ} \mathrm{C}$ for 2 days before colonies were enumerated. Each time point was replicated six times in each of two trials. After 28 weeks, the husk surrounding the inoculated nuts was assayed for $186 \mathrm{r}$ by suspending $10 \mathrm{~g}$ of husk material in $10 \mathrm{ml}$ water and then dilution plating on TSBA+rif. Sample plates were incubated at $28^{\circ} \mathrm{C}$ for 2 days before colonies were enumerated. We increased the amount of husk material sampled to enhance detection of falling $A$. tumefaciens $186 \mathrm{r}$ populations.

Populations of A. tumefaciens in the husk of artificially and naturally stratified seed were separately subjected to an ANOVA using PROC GLM. Trial was not a significant contributor to variation and, thus, data from both trials were pooled for analysis. Mean separation was accomplished using Tukeys-w.

\section{Results}

Mother block surveys. A. tumefaciens (virulent or avirulent) was never detected, using growth on the semiselective medium $1 \mathrm{~A}$, in or on seed $(n=2,560)$ directly picked from trees in the mother blocks surveyed in 2009 and 2010 (Figs. 1 and 2). In grow-out tests conducted in $2009,62 \%(n=640)$ of the seed picked directly from the trees germinated and none of the seedlings originating from these seed were symptomatic for gall formation.

Virulent and avirulent $A$. tumefaciens strains were detected on the exterior of seed placed on the orchard floor under mother trees 
(Figs. 1 and 2). The proportion of seed groups with detectable virulent and avirulent $A$. tumefaciens was positively correlated with time spent in contact with the orchard floor $\left(P<0.0001, R^{2}=\right.$ 0.582 and $P<0.0001, R^{2}=0.578$; respectively). Both virulent and avirulent $A$. tumefaciens were detected on seed having contact with the orchard floor for as little as $24 \mathrm{~h}$ in both the Stanislaus and Colusa County nurseries (Figs. 1 and 2). On average (i.e., across two orchards over two survey years), virulent and avirulent $A$. tumefaciens strains were detected on $22 \pm 7.2$ and $54 \pm 26 \%$ of the seed groups, respectively, in contact with the orchard floor for a maximum of 28 days. It should be noted that most growers limit the time seed spend on the orchard floor to significantly less than 28 days.

The surveys conducted at nursery B also were designed to compare seed placed next to symptomatic (visible crown galls) or asymptomatic trees. Detection of virulent $A$. tumefaciens was more likely on seed placed under symptomatic trees $(P=0.0046)$. No virulent $A$. tumefaciens strains were ever detected on seed incubated under asymptomatic trees $(n=8)$. Data from nursery A were not used for this comparison because all seed were placed under asymptomatic trees.

Datura. Forty-eight $D$. stramonium plants were infested with $A$. tumefaciens $186 \mathrm{r}$ either through soil or by direct inoculation via the stem wounding. When assayed, all plants were determined to harbor $186 \mathrm{r}$ in the internal portions of surface-sterilized stem segments. A. tumefaciens $186 \mathrm{r}$ was not detected in seed collected from these plants. $186 \mathrm{r}$ was not detected in noninoculated control plants or seed collected from these plants.

Greenhouse simulation; soil inoculation studies. Walnut seed used in the inoculated soil experiments were confirmed free of detectable levels of A. tumefaciens 186r at the beginning of the experiments. One day after placement on 186r-infested soil, 186r was detected on the exterior of the husk. A. tumefaciens was not detected in the interior portion of the husk until 4 days post placement on the soil surface (Fig. 3). At day 4, 5\% of the seed had detectable $A$. tumefaciens $186 \mathrm{r}$ populations in husk tissue. The chance of a given seed becoming infested with A. tumefaciens both in and on the husk increased in direct proportion to the length of time in contact with the soil. A. tumefaciens 186r was never detected inside the shell over the 108-day sampling period. Other bacteria were co-cultured with 186r on 1A. Ochrobactrum sp., Sinorhizobium sp., and Ensifer adhearans were identified in addition to avirulent $A$. tumefaciens bv.1.

Seed inoculation-stratification studies. After inoculation with A. tumefaciens $186 \mathrm{r}$ at day 0 , the seed husks harbored $4.92 \times 10^{6}$ CFU/g of husk material (Fig. 4). The husk material of artificially stratified seed (i.e., peat moss stored at $6^{\circ} \mathrm{C}$ ) remained hydrated and closely bound to the seed over the 5-month stratification period but was slightly degraded due to rot. Populations of $A$. tumefaciens $186 \mathrm{r}$ in the husk did not change significantly over the stratification period and averaged $1.23 \times 10^{7} \mathrm{CFU} / \mathrm{g}$ of husk material. The peat moss used to stratify the seed harbored $A$. tumefaciens at $1.5 \times 10^{4} \mathrm{CFU} / \mathrm{g}$ of peat moss after 5 months of stratification.

The husk material of naturally stratified nuts (i.e., in Telone C35 -fumigated field soil) dried out and peeled away from the seed over the stratification period. Populations of A. tumefaciens $186 \mathrm{r}$ in the husk declined over the stratification period but were still detectable after 147 days at $1.3 \times 10^{4} \mathrm{CFU} / \mathrm{g}$ of husk material. Interestingly, several seed had germinated during stratification and A. tumefaciens $186 \mathrm{r}$ was readily detected in the internal portions of the emergent radial after surface sterilization with $20 \%$ bleach for $20 \mathrm{~min}$. After 5 months of stratification, A. tumefaciens $186 \mathrm{r}$ was detected at a level of $1.48 \times 10^{4} \mathrm{CFU} / \mathrm{g}$ of soil in the fumigated field soil used to stratify the inoculated walnut trees.

\section{Discussion}

The surveys conducted in two separate commercial nurseries over two consecutive years demonstrate that A. tumefaciens, virulent or avirulent, does not occur or is present below culture detec- tion limits on or in seed harvested directly from nursery mother trees (Figs. 1 and 2). Collectively, 2,560 seeds were harvested directly from nursery mother trees and assayed for A. tumefaciens by plating or crown gall by grow-out. Crown gall symptomatic or asymptomatic mother trees did not influence the incidence of $A$. tumefaciens on or in seed harvested from these trees. The inability to A. tumefaciens to move from a systemically infected plant to seed was also documented using the sensitive indicator plant $D$. stramonium. However, Weller et al. (29) detected A. tumefaciens in surface-sterilized Brassica napus seed, suggesting that movement into seed of some systemically infected hosts may be possible.

Our survey found that seed in contact with the soil for as little as $24 \mathrm{~h}$ were contaminated by soilborne A. tumefaciens populations (virulent and avirulent; Figs. 1 and 2). The frequency of $A$. tumefaciens contamination of the seed increased with the length of time seed were left on the orchard floor. This is consistent with Krimi et al. (15), who demonstrated that populations of both virulent and avirulent $A$. tumefaciens strains were readily detected in nursery soil, with virulent isolates being more prevalent in spring and summer. Seasonal fluctuations of virulent/avirulent $A$. tumefaciens ratios under California nursery conditions are not known. However, we detected significant populations of virulent strains on or in the surface or husk of seed collected from the soil surface in September and October, a time period when Krimi et al. (15) failed to detect virulent isolates. In the two mother blocks surveyed, A. tumefaciens incidence on seed did not exceed $30 \%$. Seed were more likely to become contaminated if they were placed near a crown-gall-symptomatic mother tree. Regardless of $A$. tumefaciens contamination levels in or on the husk, A. tumefaciens was never detected in the interior of the seed (Figs. 1-3).

A greenhouse simulation using soil infested with a marked strain of $A$. tumefaciens $186 \mathrm{r}$ showed that $A$. tumefaciens quickly colonized the outside of the husk within 1 day and proceeded to rapidly

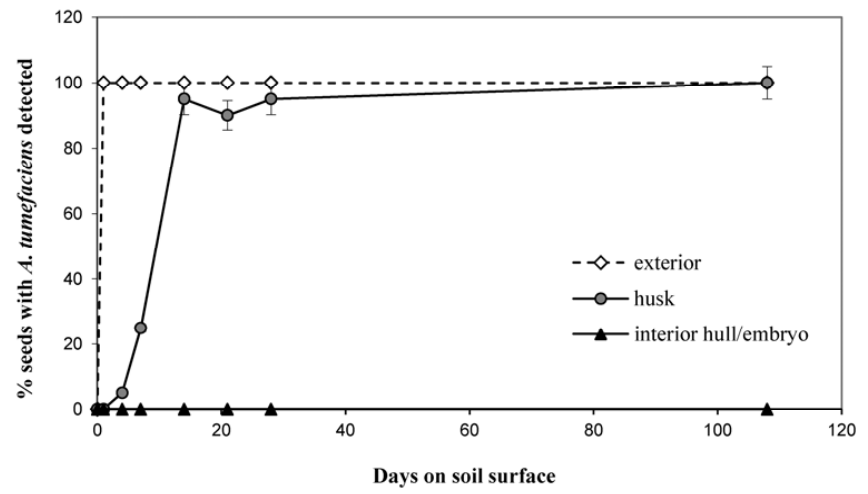

Fig. 3. Proportion of Agrobacterium tumefaciens 186r detected on the exterior, in the husk, and inside the shell of walnut seed placed onto 186r-inoculated soil. Error bars $= \pm$ standard error of the mean.

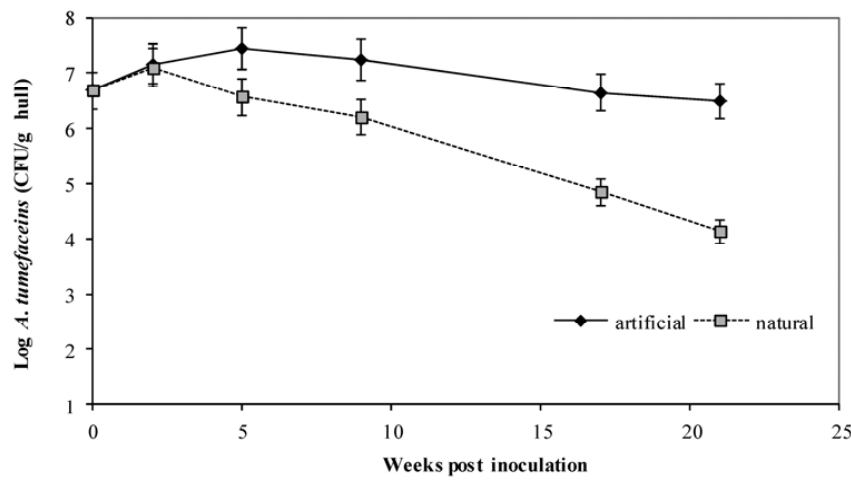

Fig. 4. Populations of Agrobacterium tumefaciens 186r in husk material during artificial and natural stratification of inoculated seed. Error bars $= \pm$ standard error of the mean. 
colonize the husk. Similar to the nursery surveys, A. tumefaciens was never detected inside the shell or embryo of the seed.

External populations of $A$. tumefaciens could hypothetically enter the seed through the suture of the seed. Under the typical nursery conditions in this study, this appears unlikely to occur with black walnut seed because A. tumefaciens was never detected within the interior of the seed. Using $D$. stramonium, a sensitive crown gall indicator plant, A. tumefaciens also was unable to colonize the interior of seed harvested from systemically infected seedlings.

Soilborne populations of A. tumefaciens in the orchard floor appear to be a significant inoculum source for A. tumefaciens contamination of Paradox hybrid seed. Avoidance of contact with the orchard floor is a simple, cost-effective strategy to limit A. tumefaciens contamination and potentially reduce crown gall incidence on Paradox seedlings under nursery conditions.

The current horticultural practice used to harvest Paradox hybrid seed for rootstock production (i.e., shaking seed to the orchard floor and then collecting them one or more days later) leads to potential exposure to soilborne populations of A. tumefaciens. However, seed can be harvested with the aid of a ground-cover tarp on the orchard floor to catch seed as they fall during the shaking process. Seed also can be harvested with a prune shaker, whose shaking mechanism is surrounded on three sides by a conveyer belt to catch the seed, which then collects them in a bin without the seed touching the nursery mother block orchard floor. Once harvested in a manner precluding soil contact, we also have shown that a dip in a cationic detergent would be a simple, cost-effective way to further suppress A. tumefaciens populations on or in the seed prior to planting (32).

In response to the data presented here, several commercial nurseries are now testing the use of groundcover tarps and prune shakers in their harvesting procedures. The long-term impact of these practices on crown gall incidence under commercial conditions is being evaluated.

\section{Acknowledgments}

This project was supported, in part, by a grant from the California Department of Food and Agriculture/Fruit Tree, Nut Tree and Grapevine Improvement Advisory Board and the United States Department of Agriculture-Agricultural Research Service CRIS project 5306-22000-015-00D. We thank R. Greenhut, A. McClean, and S. Strauss for their valuable editorial suggestions and L. Pearson for administrative support.

\section{Literature Cited}

1. Agrios, G. N. 2005. Plant Pathology, 5th ed. Elsevier Academic Press, Burlington, MA.

2. Bernaerts, M., and De Ley, J. 1967. Mechanism of the 3-ketolactose test for Agrobacterium. Arch. Mikrobiol. 56:81-90.

3. Bouzar, H., Ouadah, D., Krimi, Z., Jones, J. B., Trovato, M., Petit, A., and Dessaux, Y. 1993. Correlative association between resident plasmids and the host chromosome in a diverse Agrobacterium soil population. Appl. Environ. Microbiol. 59:1310-1317.

4. Browne, G. T., McLaughin, S. T., Hackett, W. P., McGranahan, G. H., and Leslie, C. A. 2006. Evaluation of resistance to Phytophthora citricola among diverse clones of Paradox hybrid rootstocks. Proc. Vth Int. Walnut Symp. M. E. Malvolti and D. Avanzato, eds. Acta Hortic. 705:395-400.

5. Burr, T., and Katz, B. H. 1983. Isolation of Agrobacterium tumefaciens biovar 3 from grapevine galls and sap, and from vineyard soil. Phytopathology 73:163-165.

6. Catlin, P. B. 1998. Root physiology and rootstock characteristics. Pages 7183 in: Walnut Production Manual Publication 3373. D. E. Ramos, ed. University of California Division of Agriculture and Natural Resources, Oakland.

7. Conn, H. J. 1942. Validity of the genus Alcaligenes. J. Bacteriol. 44:353-360.

8. Cubero, J., Lastra, B., Salcedo, C. I., Piquer, J., and Lopez, M. M. 2006. Systemic movement of Agrobacterium tumefaciens in several plant species. J. Appl. Microbiol. 101:412-421.

9. Deep, I. W., McNeilan, R. A., and MacSwan, I. C. 1968. Soil fumigants tested for control of crown gall. Plant Dis. Rep. 52:102-105.
10. Deep, I. W., and Young, R. A. 1965. The role of preplanting treatments with chemicals in increasing the incidence of crown gall. Phytopathology 55:212-216.

11. de León, L. Siverio, F., López, M. M., and Rodríguez, A. 2011. Clavibacter michiganensis subsp. michiganensis, a seedborne tomato pathogen: healthy seeds are still the goal. Plant Dis. 95:1328-1338.

12. Dickey, R. S. 1962. Efficacy of five fumigants for the control of Agrobacterium tumefaciens at various depths in soil. Plant Dis. Rep. 46:73-76.

13. Epstein, L. Kaur, S., McKenna, J. Grant, J., Olson, W. L., and Reil, W. 2008. Crown gall can spread between walnut trees in nurseries and reduce future yields. Calif. Agric. 62:111-115.

14. Flint, M. L., ed. 2003. Integrated Pest Management for Walnuts Publication 3270. Statewide Integrated Pest Management Program, University of California Division of Agriculture and Natural Resources, Oakland.

15. Krimi, Z., Petit, A., Mougel, C., Dessaux, Y., and Nesme, X. 2002. Seasonal fluctuations and long-term persistence of pathogenic populations of Agrobacterium spp. in soils. Appl. Environ. Microbiol. 68:3358-3365.

16. Marti, R., Cubero, J., Daza, A., Piquer, J., Salcedo, C. I., Morente, C., and Lopez, M. M. 1999. Evidence of migration and endophytic presence of Agrobacterium tumefaciens in rose plants. Eur. J. Plant Pathol. 105:39-50.

17. Moore, L. W. 1997. Latent infections and seasonal variability of crown gall development in seedlings of three Prunus species. Phytopathology 66:10971101.

18. Moore, L. W., Bouzar, H., and Burr, T. 2001. Agrobacterium. Pages 17-35 in: Laboratory Guide for the Identification of Plant Pathogenic Bacteria, 3rd ed. N. W. Schaad, J. B. Jones, and W. Chun, eds. American Phytopathological Society, St. Paul, MN.

19. Mougel, C., Cournoyer, B., and Nesme, X. 2001. Novel tellurite-amended media and specific chromosomal and Ti plasmid probes for direct analysis of soil populations of Agrobacterium biovars 1 and 2. Appl. Environ. Microbiol. 67:65-74

20. Ogawa, J. M., and English, H. 1991. Diseases of Temperate Zone Tree Fruit and Nut Crops Publication 3345. University of California Division of Agriculture and Natural Resources, Oakland.

21. Riel, W. O., Leslie, C. A., Forde, H. I., and McKenna, J. R. 1998. Propagation. Pages 71-83 in: Walnut Production Manual Publication 3373. D. E. Ramos, ed. University of California Division of Agriculture and Natural Resources, Oakland.

22. Roberts, S. J., Brough, J., and Hunter, P. J. 2007. Modeling the spread of Xanthomonas campestris pv. campestris in module-raised brassica transplants. Plant Pathol. 56:391-401.

23. Roberts, S. J., Hiltunen, L. H., Hunter, P. J., and Brough, J. 1999. Transmission from seed to seedling and secondary spread of Xanthomonas campestris pv. campestris in brassica transplants: effects of dose and watering regime. Eur. J. Plant Pathol. 105:879-889.

24. Rylander, R., and Lundholm, M. 1978. Bacterial contamination of cotton and cotton dust and effects on the lung. Br. J. Ind. Med. 35:204-207.

25. Sinclair, W. A., Lyon, H. W., and Johnson, W. T. 1987. Diseases of Trees and Shrubs. Cornell University Press, Ithaca, NY.

26. Teviotdale, B. L., and Schroth, M. N. 1998. Bark, fruit and foliage diseases. Pages 242-246 in: Walnut Production Manual Publication 3373. D. E. Ramos, ed. University of California Division of Agriculture and Natural Resources, Oakland.

27. Van der Wolf, J. M., Van der Zouwen, P. S., and Van der Heijden, L. 2013. Flower infection of Brassica oleracea with Xanthomonas campestris pv. campestris results in high levels of seed infection. Eur. J. Plant Pathol. 136:103-111.

28. Weisburg, W. G., Barns, S. M., Pelletier, D. A., and Lane, D. J. 1991. 16 S ribosomal DNA amplification for phylogenetic study. J. Bacteriol. 173:697703.

29. Weller, S. A., Simpkins, S. A., Stead, D. E., Kurdziel, A., Hird, H., and Weekes, R. J. 2002. Identification of Agrobacterium spp. present within Brassica napus seed by TaqMan PCR, implications for GM screening procedures. Arch. Microbiol. 178:338-343.

30. Yakabe, L. E., Maccree, M. M. Sudarshana, P., McClean, A. E., Parker, S. R., Wechter, W. P., Presting, G., Marutani-Hert, M., and Kluepfel, D. A. 2012. Novel PCR primers for detection of genetically diverse virulent Agrobacterium tumefaciens biovar 1 strains. J. Gen. Plant Pathol. 78:121-126.

31. Yakabe, L. E., Parker, S. R., and Kluepfel, D. A. 2010. Effect of pre-plant soil fumigants on Agrobacterium tumefaciens, pythiaceous species, and subsequent soil recolonization by A. tumefaciens. Crop Prot. 29:583-590.

32. Yakabe, L. E., Parker, S. R., and Kluepfel, D. A. 2012. Cationic surfactants: potential surface disinfectants to manage Agrobacterium tumefaciens biovar 1 contamination of grafting tools. Plant Dis. 96:409-415.

33. Yakabe, L. E., Parker, S. R., and Kluepfel, D. A. 2012. Role of systemic Agrobacterium tumefaciens populations in crown gall incidence on the walnut hybrid rootstock 'Paradox'. Plant Dis. 96:1415-1421. 